\title{
Análise sobre a judicialização da saúde no Estado de Mato Grosso no período de 2011-2012
}

\author{
Analysis of the legalization of health in the state of Mato Grosso in the period 2011-2012 \\ El análisis de la legalización de la salud en el estado de Mato Grosso, en el periodo 2011 - \\ 2012
}

Simone Cristina de Arruda ${ }^{1}$

\begin{abstract}
RESUMO: O Direito à Saúde consagrado na Carta Cidadã de 88 é um direito de todos, e segundo os doutrinadores, passível de ser exigido judicialmente quando não garantido pelo Estado. O objetivo desse trabalho é compreender o fenômeno da Judicialização do acesso à Saúde Pública no Estado de Mato Grosso. Foi utilizado o método qualitativo baseado na pesquisa documental, retirado de doutrinas jurídicas e da saúde, bem como o quantitativo através da análise dos dados fornecidos no relatório do Núcleo de Apoio Técnico-NAT instalado no Fórum, cujo escopo é subsidiar os magistrados com pareceres técnicos na área da saúde. Foi com a crescente demanda de ações judiciais envolvendo a área da saúde pública no estado de Mato Grosso e com a criação do NAT que emite pareceres técnicos a fim de subsidiar os magistrados ao decidir os casos apresentados na justiça estadual, que justificou a realização desse trabalho. É possível verificar que a população cada vez mais está consciente de seus direitos e exigindo que o mesmo seja efetivado através de decisões judiciais, visto que a ação do Poder Executivo na saúde resta ineficaz, não alcançando a população que procura por esses serviços. Enquanto não haja um debate coletivo com os atores sociais e os três poderes, quanto à situação da saúde no Estado de Mato Grosso, estaremos diante desse cenário de aumento de ações envolvendo a saúde, pois, o cidadão não pode ficar à mercê da ineficácia de gestão dos Poderes Públicos.
\end{abstract}

Palavras-chave: Judicialização. Direito à Saúde. Estado. Núcleo de Apoio Técnico.

\begin{abstract}
The right to health enshrined in the Citizen Charter 88 is a right for all, and according to the scholars, which can be enforced in court when not guaranteed by the State. The aim of this study is to understand the phenomenon Legalization of access to public health in the State of Mato Grosso. The qualitative method based on desk research, taken from legal doctrines and health was used and the amount by analyzing the data provided in the Technical NAT Support Center report installed in the Forum, whose purpose is to assist the judges with technical advice in the health area. It was with the increasing demand of lawsuits involving the area of public health in the state of Mato Grosso and the creation of NAT issuing technical advice in order to support the judges to decide cases brought in state courts, which justified the realization of this work. You can check that is increasingly aware population of their rights and demanding that it be effected through judicial decisions, as the action of the executive power on health remains ineffective, not reaching the population that demand for these services. While there is no public debate with stakeholders and the three powers, as the health situation in the State of Mato Grosso, we will stand before this increase scenario
\end{abstract}

\footnotetext{
${ }^{1}$ Universidade Federal de Mato Grosso. E-mail: siarruda.adv@gmail.com
} 
of actions involving health, because the citizen cannot be at the mercy of the ineffectiveness of management of public authorities.

Keywords : Legalization. Right to Health. State. Core Support.

RESUMEN: El derecho a la salud consagrado en la Carta 88 ciudadana es un derecho para todos, y de acuerdo con los estudiosos, los cuales pueden ser aplicadas en la corte cuando no garantizada por el Estado. El objetivo de este estudio es comprender el fenómeno de la legalización de acceso a la salud pública en el Estado de Mato Grosso. Se utilizó el método cualitativo basado en la investigación documental, tomada de las doctrinas legales y de salud y la cantidad mediante el análisis de los datos proporcionados en el informe Centro de Soporte Técnico NAT instalado en el Foro, cuyo propósito es ayudar a los jueces con el asesoramiento técnico en la salud. Fue con la creciente demanda de demandas relacionadas con el área de la salud pública en el estado de Mato Grosso y la creación de NAT emisión de asesoramiento técnico con el fin de apoyar a los jueces para decidir los casos presentados en los tribunales estatales, lo que justifica la realización de este trabajo. Se puede comprobar que es población cada vez más conscientes de sus derechos y exigiendo que se efectuará a través de decisiones judiciales, como la acción del poder ejecutivo en la salud sigue siendo ineficaz, no llegar a la población que la demanda de estos servicios. Si bien no hay debate público con las partes interesadas y los tres poderes, como la situación de salud en el Estado de Mato Grosso, estaremos delante de este aumento escenario de las acciones relacionadas con la salud, debido a que el ciudadano no puede estar a merced de la ineficacia de gestión de las autoridades públicas.

Palabras-Ilave: La legalización. Derecho a la Salud. Estado. Soporte del Núcleo.

\section{Introdução}

A Saúde Pública hodiernamente encontra-se desfalecida pelo Poder Público. Sendo esse o principal assunto nas discussões de qualquer segmento da sociedade.

Existe hoje uma crescente demanda de ações judiciais com pedidos relacionados à área de saúde. A falta de capacidade de atendimento, por parte do Estado, provocou um fato jurídico, conhecido como Judicialização da Saúde. Busca-se com a judicialização a efetividade no atendimento de saúde por meio das decisões judiciais que sentenciam que o Estado atenda o usuário-cidadão naquilo que entende como direito subjetivo.

Os números apresentados no relatório do Núcleo de Apoio Técnico (NAT) de Mato Grosso, utilizados nesta pesquisa, revelam que os pedidos de judicialização estão, em maior parte, pautados em cirurgias ou procedimentos médicos, medicamentos e exames.

Diante desse cenário, chega-se ao seguinte questionamento: essa busca pelo Poder Judiciário é um sinal de fortalecimento das Instituições Democráticas, ou é sinal de 
prematuridade das instituições políticas, que deveriam promover debate coletivo acerca da efetividade da saúde pública?

O objetivo geral do presente trabalho é compreender o fenômeno da Judicialização do acesso à Saúde Pública no Estado de Mato Grosso. E, especificamente, busca-se apurar a quantidade de ações ajuizadas pelo usuário-cidadão, comparar as decisões judiciais que foram deferidas ou indeferidas em relação ao número de ações ajuizadas em cada período, além de verificar a natureza do pleito e o tipo de representação. Este artigo está organizado da seguinte maneira: além da Introdução, o tópico "2" trata do Direito à Saúde; a Reforma Sanitária Brasileira e a VIII Conferência Nacional de Saúde; o conceito de Saúde, segundo a Organização Mundial de Saúde, e o conceito decorrente da VIII Conferência Nacional de Saúde; o Sistema Único de Saúde criado pela Constituição de 1988; a Eficácia do Direito à Saúde, sendo este passível de ser tutelado judicialmente quando não garantido; o Fenômeno da Judicialização da Saúde; a Saúde no Estado de Mato Grosso de 2011-2012 e o Papel do NAT, já o tópico "3" é abordado os procedimentos metodológicos utilizados para desenvolver a pesquisa, e por fim, no tópico "4" a análise e discussão dos resultados.

\section{Conceito de saúde}

Para a Organização Mundial de Saúde (OMS), "saúde não é apenas ausência de doença, mas a situação de perfeito bem-estar físico, mental e social” (1). Existe uma crítica quanto à definição acima exposta, pois o bem-estar diz respeito a algo subjetivo e difícil de ser conceituado, tendo em vista a diversidade cultural, social e política da nação.

Na VIII Conferência Nacional de Saúde de 1986, a definição dada à saúde foi: "é a resultante das condições de alimentação, habitação, educação, renda, meio-ambiente, trabalho, transporte, emprego, lazer, liberdade, acesso à terra e posse dela, além da obtenção a serviços de saúde" (2)

Esse conceito da VIII Conferência é mais adequado para a nossa realidade, em virtude de sua abrangência. Percebe-se que a Constituição Federal de 1988 não fornece uma definição explícita de saúde, mas leva-nos a interpretá-la de forma mais condizente com o conceito definido na Conferência.

Para Sarlet "o direito à saúde tem sido considerado como dependente de intermediação legislativa, de tal sorte que não são poucos os que the negam a sua plenitude eficacial". (3) 
Já os Tribunais Superiores, notadamente o STF, "passaram a reconhecer a saúde como direito subjetivo exigível em Juízo e não mais como direito enunciado de modo eminentemente programático" (3).

\section{Os Direitos Fundamentais Sociais na Constituição de 1988}

A doutrina classifica os Direitos Fundamentais em gerações de direitos, e também utiliza a expressão "dimensões". Esses passam ter a seguinte definição, segundo Lenza "Direitos Humanos de Primeira Geração, Direitos Humanos de Segunda Geração, Direitos Humanos de Terceira Geração, Direitos Humanos de Quarta Geração". (4)

Englobado nos Direitos Humanos de Segunda Geração, estão os Direitos Sociais.

Os direitos Sociais, Direitos Fundamentais de $2^{a}$ Geração, são definidos por Silva, como sendo:

(...) prestações positivas proporcionadas pelo Estado direta ou indiretamente, enunciadas em normas constitucionais, que possibilitam melhores condições de vida aos mais fracos, direitos que tendem a realizar a igualização de situações sociais desiguais. (5)

Os Direitos de $2^{\underline{a}}$ Geração nada mais são do que prestações positivas, com a finalidade de garantir uma igualdade material àqueles que, sozinhos, não conseguiriam prover de tais condições.

Por derradeiro, diante dos diversos conceitos acima definidos, depreende-se que o direito social exige uma atuação positiva do Estado, a fim de equalizar as desigualdades sociais e de redistribuir melhor os recursos existentes, ou seja, é um direito a uma prestação material por parte do Estado.

\section{Direito à saúde: $3^{\text {a }}$ e $8^{\text {a }}$ Conferências Nacionais de Saúde e a Reforma Sanitária Brasileira}

A Saúde ganhou preceito de Direito Fundamental Social só com a Carta Cidadã de 1988. Já a Constituição Federal de 1934 trouxe a proteção à saúde associada ao direito do trabalho, e a Carta Federal de 1937 trouxe a proteção à saúde da criança. No período da ditadura militar, a Constituição Federal de 1946, apenas abordou a competência da União para tratar sobre a proteção da saúde, e na Constituição de 1967, além do dispositivo já 
previsto na Constituição anterior, a competência da União para estabelecer Planos Nacionais de Saúde.

A Constituição Federal/88 trouxe, em seu art. 6º, o seguinte preceito:

São direitos sociais a educação, a saúde, a alimentação, o trabalho, a moradia, o lazer, a segurança, a previdência social, proteção à maternidade e à infância, a assistência aos desamparados, na forma desta Constituição". (6)

Assim como trouxe, nos artigos 196 a 200, previsões a respeito da competência do ente federativo em relação à saúde, bem como algumas competências do Sistema Único de Saúde.

A análise do sistema de saúde antes da CF/88 é bem explicitada por Figueiredo da seguinte maneira:

Anteriormente, a assistência médica estava a cargo do Instituto Nacional de Assistência Médica da Previdência Social (INAMPS) e a saúde não era considerada um direito social sendo adotado um modelo de saúde que até então dividia os brasileiros em três categorias: os que podiam pagar por serviços de saúde privados; os que tinham direito à saúde pública por serem segurados pela previdência social (trabalhadores com carteira assinada); e os que não possuíam direito algum, estes eram atendidos apenas por serviços filantrópicos. (7)

Foi com a 3 $3^{\text {a }}$ Conferência Nacional de Saúde que se pensou na tese da municipalização, a fim de descentralizar as ações básicas de saúde, bem como criar uma estrutura sanitária flexível com o escopo de atender as diferenças regionais sejam elas políticas, econômicas ou sociais. (8)

As propostas debatidas na $3^{\text {a }}$ Conferência giraram em torno também da questão de implementação de uma Política Nacional de Saúde, com o propósito de garantir saúde para toda a população, o que mais tarde serviu de subsídio para a reforma sanitária.

O movimento da Reforma Sanitária Brasileira nasceu na luta contra o regime ditatorial e consolidou-se na $8^{\circ}$ Conferência Nacional de Saúde 1986. Esses movimentos foram fundamentais para a transformação sanitária e social, conscientizando a população de que a saúde deveria ser um direito assegurado a todos e como responsável para garanti-lo, o Estado.

O editorial da Associação Brasileira de Saúde Coletiva- ABRASCO, citado por Paim, trazia: 


\begin{abstract}
A ABRASCO, engajada nesta luta, assume a bandeira da reforma sanitária, como a condição de viabilidade da conquista do direito universal à saúde. Reforma que implicará na reformulação das políticas públicas e do aparelho governamental burocrático que estão diretamente ligadas às condições de vida. Reforma que pressupõe o aprofundamento da consciência sanitária e no controle sobre os órgãos definidores e implementadores da política de saúde. Reforma que exigirá uma nova ética dos profissionais do setor no tratamento do usuário como cidadão na plenitude do exercício dos seus direitos. Neste sentido, a ABRASCO promoverá o I Congresso Brasileiro de Saúde Coletiva, cujo tema central será "Reforma Sanitária: garantia do direito universal à saúde, como parte dos esforços comuns na continuidade deste processo, buscando canalizar a produção científica e a experiência política alcançadas para a formulação de um projeto de transformação que será a Reforma Sanitária Brasileira. (9)
\end{abstract}

Esse movimento denominado Reforma Sanitária diz respeito às reformulações propostas no sentido de ampliar o conceito de Saúde e rever a legislação relativa às ações de promoção, proteção e recuperação da saúde, e contribuiu para a unificação do sistema de saúde e a hierarquização e descentralização para os estados e municípios.

A VIII Conferência Nacional de Saúde ocorreu entre os dias 17 e 21 de março de 1986 em Brasília, e contou com a participação de profissionais da área da saúde, gestores e representantes de todos os seguimentos da sociedade civil. Desse encontro saíram diversas propostas, entre elas a criação de um Sistema Único Descentralizado de Saúde (SUDS), o que mais tarde tornou-se o Sistema Único de Saúde (SUS), além da redefinição do conceito de saúde, que não se limita a ausência de doenças, nem tampouco a um bem-estar físico, mental e social, mas extrapola e engloba outros direitos sociais que se destinam a garantir a dignidade da pessoa humana.

Foi devido a esses movimentos e pressões sobre o poder estatal que hoje todos têm a garantia do direito à saúde. "O Sistema Único de Saúde adotado pela CF/88 é uma referência mundial em atenção à saúde pública" (10), mas tem muito a ser feito através das políticas públicas e econômicas.

\title{
O Sistema Único de Saúde - SUS
}

Com a Constituição Federal de 1988, o Sistema Único de Saúde foi criado, e a saúde passou a ser direito de todos, sendo garantido o acesso universal e igualitário por meio das ações e serviços de saúde. 
Essa mudança da forma de gestão da saúde adotada pelo Estado, incluindo sua participação, que antes da CF/88 não existia, foi de fundamental importância para que, hoje, o SUS possa garantir tanto a ricos quanto a pobres o acesso a serviços de saúde pública.

O Brasil avançou muito, se comparado a outros países desenvolvidos, em relação à saúde pública, pois até os Estados Unidos, considerado uma potência mundial, ainda apresenta um sistema de saúde parecido com o que tínhamos antes da CF/88, e "cerca de 47 milhões de americanos estão excluídos do sistema de saúde pública". (11)

A CF/88 trouxe normas gerais sobre o SUS, e foi a Lei 8.080/1990 conhecida como "Lei Orgânica da Saúde" que normatizou o modo como ocorreria a organização e o funcionamento da promoção, proteção e prevenção dos riscos à saúde, bem como disciplina as atribuições e competências do poder executivo na saúde, nas três esferas de governo: nacional, estadual e municipal.

O SUS é constituído pelo conjunto das ações e de serviços de saúde sob a gestão pública. Está organizado em redes regionalizadas e hierarquizadas e atua em todo o território nacional. (11)

Para Paim, o conhecimento do conteúdo da sigla SUS - Sistema Único de Saúde "não possibilita um entendimento imediato de seu significado". (11)

Destarte, para esclarecer o que é o SUS, o autor define sistema de saúde como sendo um "conjunto de agências e agentes, cuja atuação tem como objetivo principal garantir a saúde das pessoas e das populações". (11)

As agências, segundo o mesmo autor, "são organizações públicas ou privadas, governamentais ou não, que têm como finalidade promover, proteger, recuperar e reabilitar a saúde dos indivíduos e das comunidades" (11).

Já os agentes são conceituados como "profissionais e demais trabalhadores de saúde que, individualmente ou em equipe, realizam ações de saúde, cuidando das pessoas e das comunidades". (11)

E por fim, os serviços de saúde que, segundo a definição de Jairnilson, "envolvem o exercício legal da medicina e de outras profissões, cujo fim explícito é preservar ou restaurar a saúde, individual e coletiva" (11).

Entendemos portanto, e de forma simplificada, pois o objetivo desse trabalho não é estudar profundamente o SUS, que o sistema de saúde é formado por todos esses atores 
sociais, como os profissionais da área que atuam nas organizações públicas e privadas a fim de garantir a saúde de toda essa coletividade que busca os serviços de saúde.

\section{Eficácia do Direito à Saúde}

O direito à saúde pode ser classificado como direitos de defesa (negativos) e direitos às prestações (positivos) acarretando reflexos na eficácia e efetividade do direito à saúde.

\section{Segundo Sarlet}

o direito à saúde, como direito de defesa, pode ser considerado no sentido de impedir ingerências indevidas por parte do Estado e terceiros na saúde do titular, e como direito a prestações, impondo ao Estado a realização de políticas que busquem a efetivação deste direito para a população, tornando, para além disso, o particular credor de prestações materiais que dizem com a saúde, tais como atendimento médico e hospitalar, fornecimento de medicamentos, realização de exames da mais variada natureza, enfim toda e qualquer prestação indispensável para a realização concreta deste direito à saúde. (12)

Os direitos de defesa, também denominados direitos negativos, exigem uma omissão do Estado ou de terceiros em não afetar a saúde das pessoas, pois entende-se que a saúde está protegida contra qualquer agressão. Já os direitos às prestações materiais, também considerados como direito positivo, são as possibilidades que o indivíduo tem de exigir do Estado a concessão de um serviço ou medicamento para a manutenção de sua saúde.

Muito se discute se o Poder Judiciário está autorizado a atender essas demandas e conceder aos particulares, via ação judicial, o direito à saúde como prestação positiva do Estado, abordaremos este assunto no tópico seguinte, trazendo posicionamentos favoráveis à atuação do judiciário.

Aquele que pleiteia a medida (fornecimento de medicamentos, cirurgias, leitos de UTI's), na maioria das vezes, não possui condições financeiras favoráveis, e até o acesso à justiça é mais dificultoso, sendo, pois, carecedor dos direitos que possui e daquilo que se pode exigir.

A eficácia Constitucional do direito à saúde está atrelada ao princípio da dignidade humana e ao direito à vida. Sem saúde o indivíduo não possui o mínimo de dignidade para viver e sustentar a si próprio.

Para Sarlet, os direitos sociais, nele incluído o direito à saúde,

apresenta caráter de norma-princípio, de tal sorte que se constitui em uma espécie de mandado de otimização, impondo aos órgãos estatais a tarefa 
de reconhecerem e imprimirem às normas de direitos e garantias fundamentais a maior eficácia e efetividade possível. (12)

O direito à saúde "deve ser encarado como direito fundamental social subjetivo, passível de ser tutelado judicialmente, caso o Estado não promova as prestações materiais necessárias à sua completa realização". (13)

A formulação, a manutenção e a implementação das políticas públicas (sociais e econômicas) de saúde, por parte do poder público, estão vinculadas à eficácia do direito à saúde, pois, em caso de omissão, a administração, retirando do indivíduo a garantia constitucional, tem por consequência a atuação do Poder Judiciário, intervindo com o escopo de, coercitivamente, exigir que o Estado garanta um direito material.

Hoje, o Poder Judiciário é visto "como o novo meio de efetivação do direito à saúde". (13).

Para Ventura et.al.:

"no debate jurídico atual, há três posições sobre a eficácia do direito à saúde, que se desdobram em análises acerca das possibilidades de atuação do Judiciário na determinação de prestações a serem cumpridas pelo SUS, quais sejam:

1. Uma primeira posição entende que a eficácia desse direito deve ser restrita aos serviços e insumos disponíveis do SUS, determinados pelo gestor público;

2. Uma segunda compreende que o direito à saúde implica garantia do direito à vida e integridade física do indivíduo, devendo o judiciário considerar a autoridade absoluta do médico que assiste ao autor da ação judicial, obrigando o SUS, a fornecer o tratamento indicado;

3. Uma terceira posição defende que a eficácia do direito à saúde necessita ser a mais ampla possível, devendo o Judiciário - na análise do caso concreto - ponderar direitos, bens e interesses em jogo, para fixar o conteúdo da prestação devida pelo Estado". (14)

Para a autora "a terceira posição é a que se revela mais adequada à compreensão da sinergia entre saúde e direito, na garantia do cidadão ao acesso à justiça e acesso à saúde" (14).

\section{Fenômeno da Judicialização da Saúde}

O fenômeno da judicialização do direito à saúde vem crescendo em virtude das inúmeras demandas judiciais que chegam ao poder judiciário, exigindo concessão de medicamentos, tratamentos, entre outros. 
Tudo isso ocorre, tendo em vista que o Estado falha na implementação ou manutenção das políticas sociais e econômicas ligadas à saúde.

Gontijo explana,

\begin{abstract}
"nesse contexto de precariedade e insuficiência da assistência à saúde pública, aliado à incapacidade do modelo operacional do SUS, pela sua própria abrangência e complexidade, de concretizar o direito à saúde, avoluma-se o ajuizamento crescente de ações judiciais para garantia infraconstitucional de cumprimento e efetivação das políticas públicas referentes ao direito à saúde". (15)
\end{abstract}

"Por políticas públicas, entende-se as ações devidas pela Administração Pública no sentido de conferir efetividade aos direitos consagrados pela Constituição". (15)

Para Paim,

Questões como a produção e a distribuição da riqueza e da renda, emprego, salário, acesso à terra para plantar e morar, ambiente, entre outras, influem sobre a saúde dos indivíduos e das comunidades, embora integrem as políticas econômicas. A educação, cultura, esporte, lazer, segurança pública, previdência e assistência social são capazes de reduzir o risco às doenças e agravos, compondo as políticas sociais. (9)

Frequentemente surgem questionamentos quanto à atuação do Poder Judiciário em atuar como "legislador positivo" (13), efetivando os direitos à saúde, quando estes não são implementados pelo Poder Executivo. E tal fenômeno jurídico traz à baila a discussão quanto à infringência do princípio da separação dos poderes.

Conforme dizeres de Gandini,

A implementação de políticas públicas por determinação judicial não representa invasão de poderes nem ofensa à Constituição Federal, pois realizada dentro das peculiaridades do caso concreto e lastreada na dignidade da pessoa humana, ou seja, pela necessidade de preservação do núcleo essencial dos direitos fundamentais, em que se inserem os chamados direitos de subsistência, quais sejam, saúde, moradia, educação e alimentação. Além disso, é preciso reconhecer que a atividade implementadora do Poder Judiciário não Ihe autoriza criar políticas públicas, mas apenas implementar as já existentes. (13)

A atuação da sociedade, que busca no Poder Judiciário a satisfação de ver reconhecido um direito consagrado na Constituição Federal ou em lei infraconstitucional e até mesmo em tratados internacionais, dos quais o Brasil seja signatário, propicia uma maior participação cidadã, na luta em busca de melhores garantias individuais e coletivas, no sentido do judiciário exigir da administração a implementação das políticas públicas. 
Alguns autores, como Barroso, apresentam ainda outra questão, quanto à judicialização do direito à saúde, a qual trata das condenações que o Estado sofre, sendo obrigado a custear determinado tratamento ou fornecer medicamento, sem previsão dos recursos disponibilizados, causando transtornos orçamentários. (16)

Para o autor

"ais decisões privam a Administração da capacidade de se planejar, comprometendo a eficiência administrativa no atendimento ao cidadão. Cada uma das decisões pode atender às necessidades imediatas do jurisdicionado, mas, globalmente, impediria a otimização das possibilidades estatais no que toca à promoção da saúde pública. (16)

A omissão do Estado na implementação das políticas públicas sociais e econômicas traz prejuízo no seu planejamento, sendo obrigado a conceder à medida pleiteada pelo jurisdicionado, independentemente dos recursos disponibilizados, pois, quando se fala no princípio da dignidade humana e no direito à vida, estes se sobrepõem ao orçamento público disponível.

\section{A Saúde no Estado de Mato Grosso 2011-2012 e o Papel do NAT (Núcleo De Apoio Técnico)}

O recorte da saúde no Estado de Mato Grosso, abordado nesse trabalho, situa nos leitos públicos e na oferta de medicação de alto custo. Foram nessas duas áreas que se percebeu maior fragilidade ao estudar o assunto.

Segundo a Organização Mundial de Saúde, o índice ideal de leitos são de 3 a 5 para cada mil habitantes.

Buscou-se informações quanto ao número de leitos públicos existentes para a região de Mato Grosso para cada mil habitantes. É importante esclarecer que os leitos públicos são voltados unicamente para a população que não possui planos de saúde. 
Figura 1. Número de leitos públicos na região de Mato Grosso nos anos de 2011 a 2012.

Número de leitos hospitalares por habitante - CNES/MS

Leitos exist. públ p/1.000 hab por Região segundo Região

Unidade da Federação: Mato Grosso

Região: Região Centro-Oeste

Período: 2011

Região

Região Centro-Oeste

Total

TOTAL

0,81

Fonte: Ministério da Saúde/SAS - Cadastro Nacional de Estabelecimentos de Saúde (CNES)

Notas:

1. Para 2005, foi considerada a situação de dezembro/2005; para os demais anos, foi considerada a média de janeiro a dezembro.

2. Não há dados para 2004 em função da implantação do sistema CNES e mudanças nas classificações de leitos.

3. Veja a Nota Técnica Informativa sobre a redução de leitos.

Fonte: Portal da saúde/DATASUS

Depreende-se do resultado da figura 1 que o Estado de Mato Grosso está fora do número ideal de leitos preconizado pela OMS para cada mil habitantes, o que gera as diversas ações judiciais exigindo leitos, consequência da falta de investimento para aumento no número de leitos no Estado de Mato Grosso.

Outra área muito afetada no Estado é a assistência à saúde, incluindo a oferta de medicamentos de alto custo à população. A Secretaria Estadual de Saúde passou para a Organização Social de Saúde (OSS) Instituto Pernambucano de Assistência Social (IPAS) em julho de 2011. A função do IPAS é gerenciar a logística de distribuição de medicamentos.

A Contratação da OSS tinha como promessa destituir a cultura da judicialização e passar para um atendimento mais humanizado e mais socializado em todo o Estado.

Um dos maiores problemas enfrentados pela Secretaria Estadual de Saúde é o volume de usuários que exigem judicialmente o cumprimento da compra de medicamentos. 
Em julho de 2011, o número de processos atingia 70\% dos usuários. Diante desse cenário de caos na saúde pública no Estado de Mato Grosso, estimulado pelos exemplos de outros estados que começaram a implementar núcleos de apoio aos magistrados em casos que envolvessem ações ligadas à saúde pública, o Tribunal de Justiça inovou e criou o Núcleo de Apoio Técnico.

O NAT, criado pelo Tribunal de Justiça do Estado de Mato Grosso/TJMT em parceria com a Secretaria Estadual de Saúde/SESMT, tem como escopo dar suporte técnico aos juízes e desembargadores nos processos de demandas na área da saúde.

O NAT é composto por médicos e farmacêuticos cedidos para o TJMT. A sua implantação foi uma alternativa para a Judicialização da Saúde, proposta pelo Juiz Túlio Duailibi Alves de Souza, de Sinop/MT.

O Núcleo foi instalado em 09 de novembro de 2011, no Fórum Desembargador José Vidal, com a função de oferecer informações técnicas da área de saúde, que servissem de subsídios para que os magistrados do Estado de Mato Grosso decidissem adequadamente em processos sobre questões relacionados ao setor. A instalação do NAT estava prevista no Termo de Cooperação Técnica assinada entre o Presidente do Tribunal de Justiça, desembargador Rubens de Oliveira Santos Filho, e o secretário de Estado de Saúde, Pedro Henry, em 20 de setembro de 2011.

Os pareceres realizados pelo NAT estão submetidos a prazos para cada demanda, quais sejam:

Os processos que tenham por objetivo a disponibilização de leitos em Unidades de Terapia Intensiva (UTIs), os pareceres deverão ser encaminhados ao juiz responsável em, no máximo, seis horas. Ou, no caso de impossibilidade justificada, no mesmo dia da solicitação. No caso dos processos cujo intuito seja a realização de procedimentos em pacientes que já se encontram internados, o parecer deverá ser encaminhado em, no máximo, 24 horas. E nos casos de procedimentos eletivos (sem urgência), o parecer poderá ser encaminhado ao magistrado em até 72 horas. (17)

\section{Procedimentos metodológicos}

O trabalho foi desenvolvido através de pesquisa quali-quantitativa. A qualitativa foi baseada na pesquisa documental, com base na doutrina jurídica e na área da saúde. Já a pesquisa quantitativa se deu através da análise dos dados fornecidos no relatório do Núcleo de Apoio Técnico do Fórum da Capital de Mato Grosso, em arquivo digital, fornecidos pelo próprio Núcleo. 
O estudo está pautado no método dedutivo, que parte das teorias e leis mais gerais para a ocorrência de fenômenos particulares. Assim como também o método de procedimento bibliográfico e documental. (18)

Esta pesquisa tem caráter descritivo, que tem por escopo descrever com exatidão os fatos e fenômenos de determinada realidade.

A pesquisa fará uso de dados relacionados à Judicialização da Saúde, número de ações ajuizadas e número de decisões concedendo ou não a medida pleiteada.

A amostra da pesquisa se apropriou dos dados de 2011 e 2012, considerando que as atividades do NAT iniciaram em novembro de 2011. A pesquisa se fundamentou nesses anos, tendo em vista que os relatórios após esse período não foram realizados pelo Núcleo, o que causou limitação ao trabalho em registrar os retrocessos e/ou avanços que ocorreram nos anos seguintes em relação às ações que demandaram a saúde pública. Esses dados dificultaram a análise das demandas apresentadas pelo Núcleo.

\section{Discussão}

Foram utilizadas informações acerca das ações ajuizadas no Fórum da Capital disponibilizadas pelo NAT através de relatórios dos anos de 2011 e 2012 em documentos digitais.

\section{Relação de Processos 2011}

Considerando o início das atividades em novembro de 2011, mais especificamente a partir do dia 16 de novembro de 2011 a 07 de dezembro de 2011 . Foram contabilizadas 86 demandas. 
Figura 2. Tipo de Representação

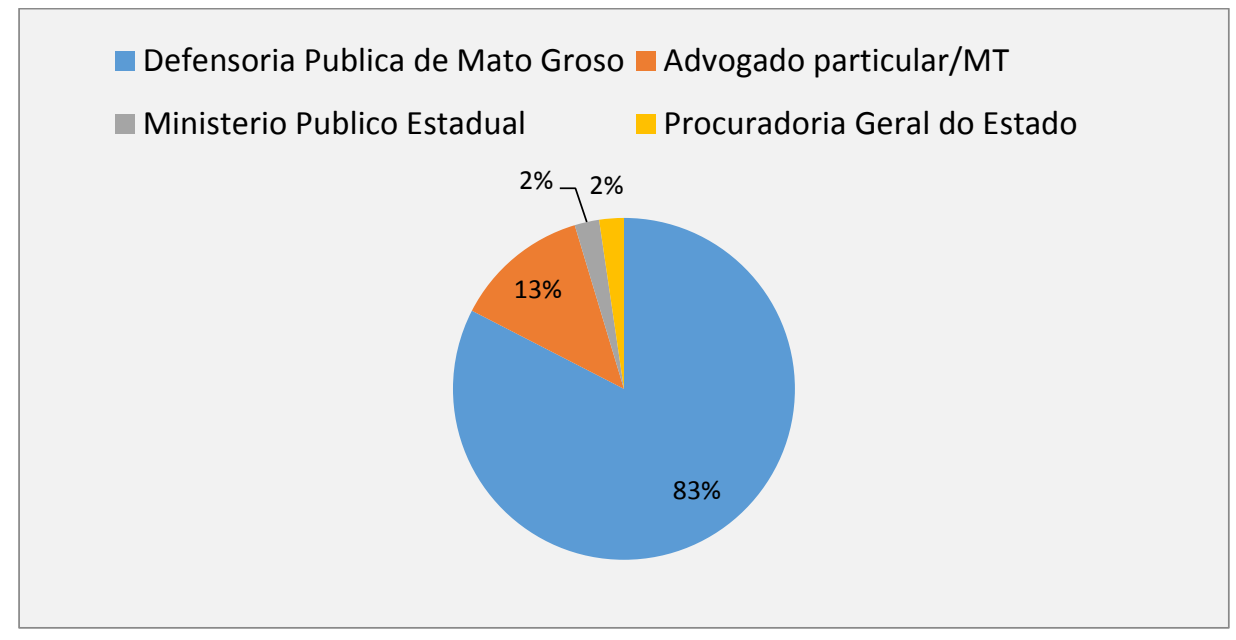

Fonte: Relatório NAT 2011.

Dos 86 processos que passaram pelo NAT, $87 \%$ (71) processos foram representados pela Defensoria Pública, 13\% (11) através de advogados particulares, e 2\% (2) processos por cada órgão, sendo: Ministério Público Estadual e Procuradoria Geral do Estado. Depreende-se que, o cidadão consciente tem buscado utilizar dos instrumentos mais viável, como a defensoria através da justiça gratuita.

Figura 3. Origem dos Processos

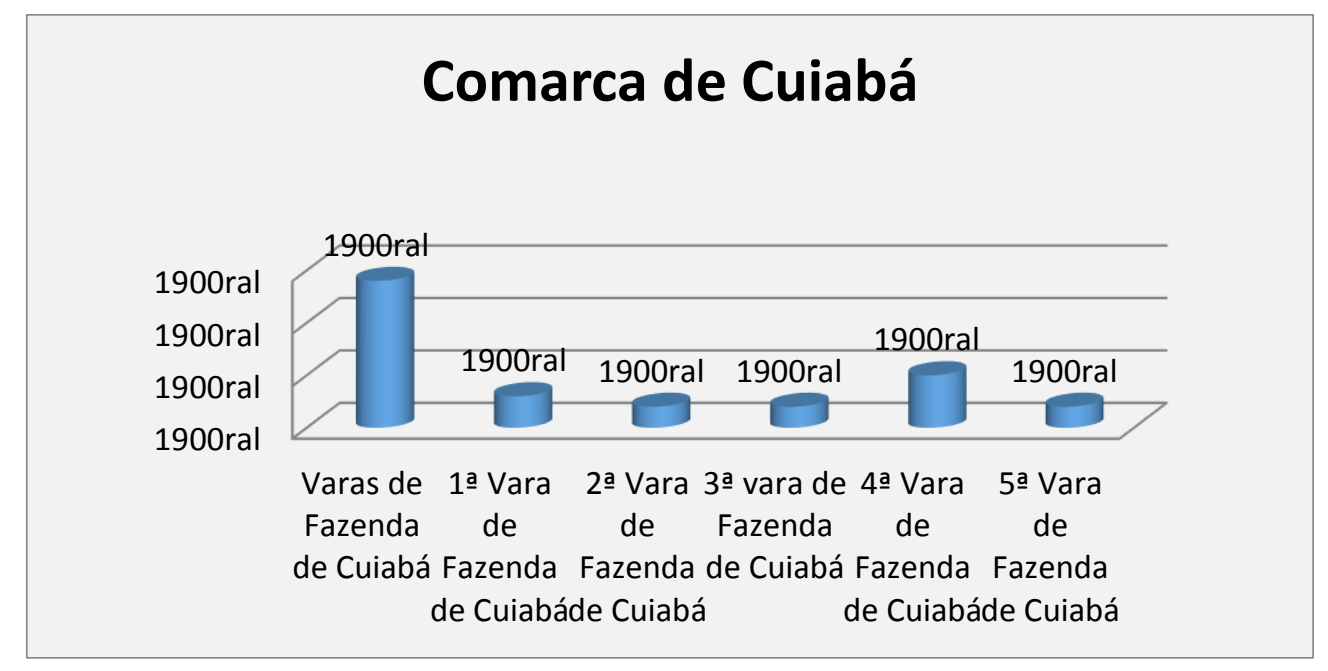

Fonte: Relatório NAT 2011

Foram oriundos da Comarca de Cuiabá 56 processos, do total de 86 processos. 
Figura 4. Origem dos Processos segundo a comarca de origem

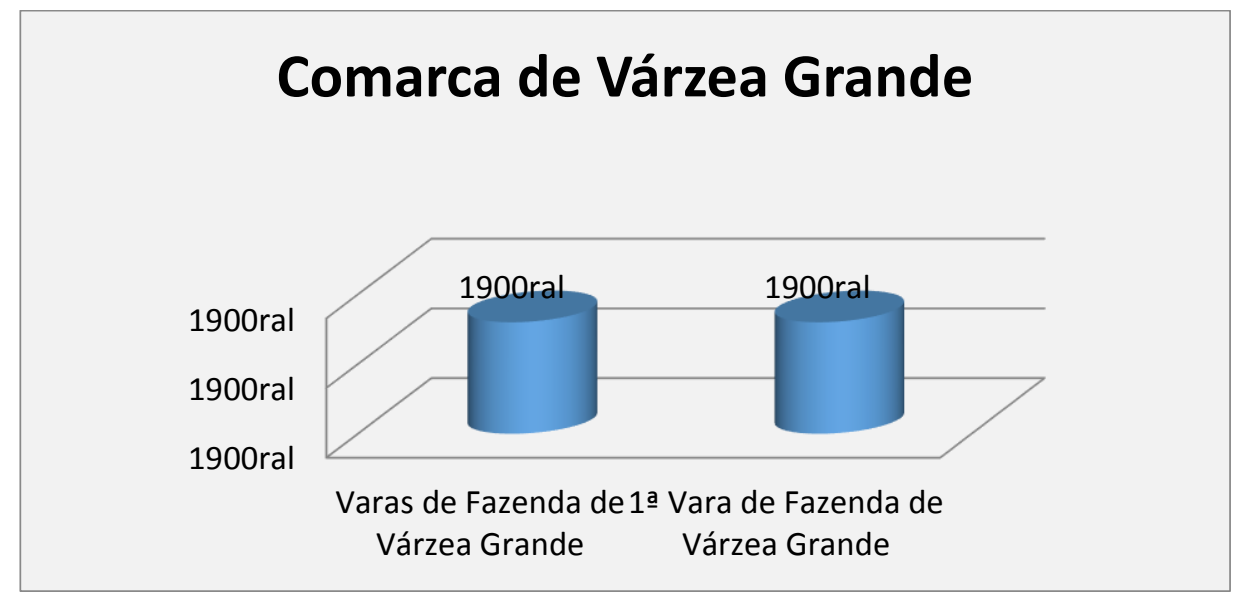

Fonte: Relatório NAT 2011

Da 1르 Vara Especializada de Fazenda de Várzea Grande originaram 8 (oito) processos.

Figura 5. Origem dos processos segundo a comarcas do interior do Estado

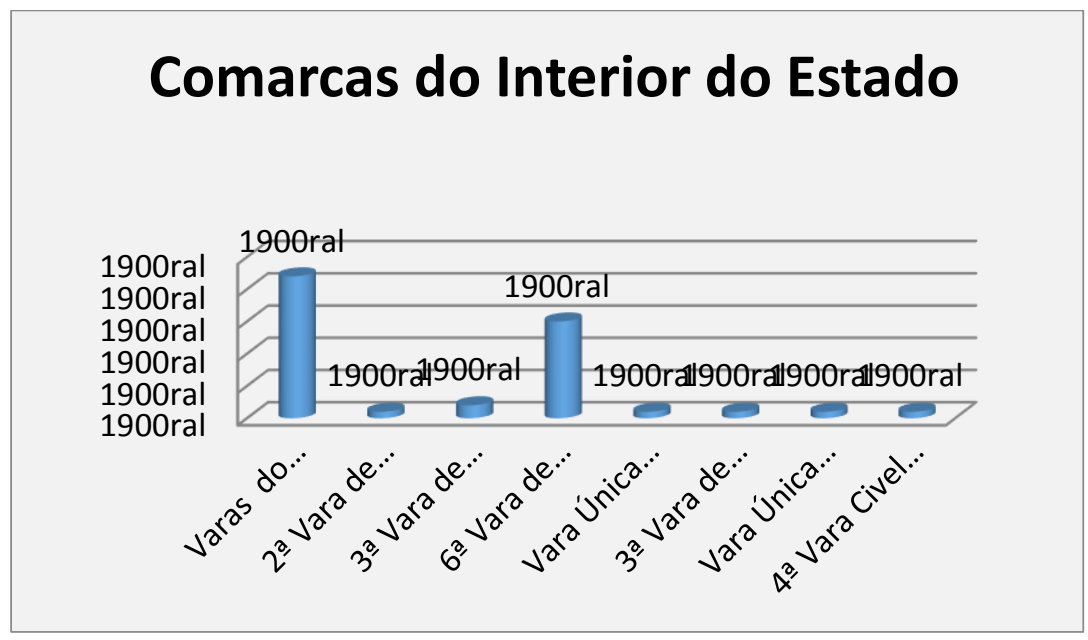

Fonte: Relatório NAT 2011

Das Comarcas do Interior do Estado de Mato Grosso originaram 22 (vinte e duas) demandas, como demonstrado no gráfico acima.

Depreende-se que o maior número de processos fora advindo da Comarca de Cuiabá. 
Figura 6. Decisão do Magistrado frente ao Pleito

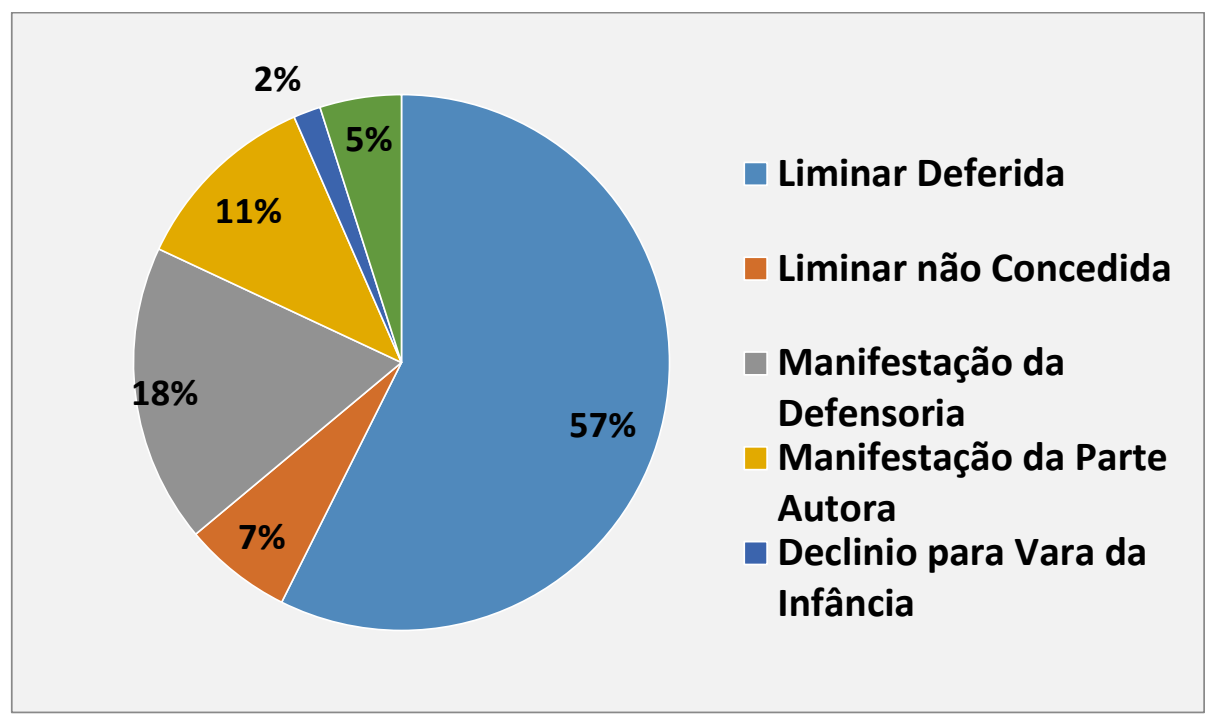

Fonte: Relatório NAT 2011

Na figura 6, temos a representação da decisão do magistrado frente ao pleito, sendo que: $57 \%$ foram liminares deferidas, $18 \%$ manifestação da Defensoria, $7 \%$ liminar não concedida, $11 \%$ manifestação da parte autora, 2\% declínio para Vara da infância e 5\% solicitação do Município em Gestão Plena em atendimento ao SUS.

Figura 7. Citação do Parecer do NAT na Decisão do Magistrado

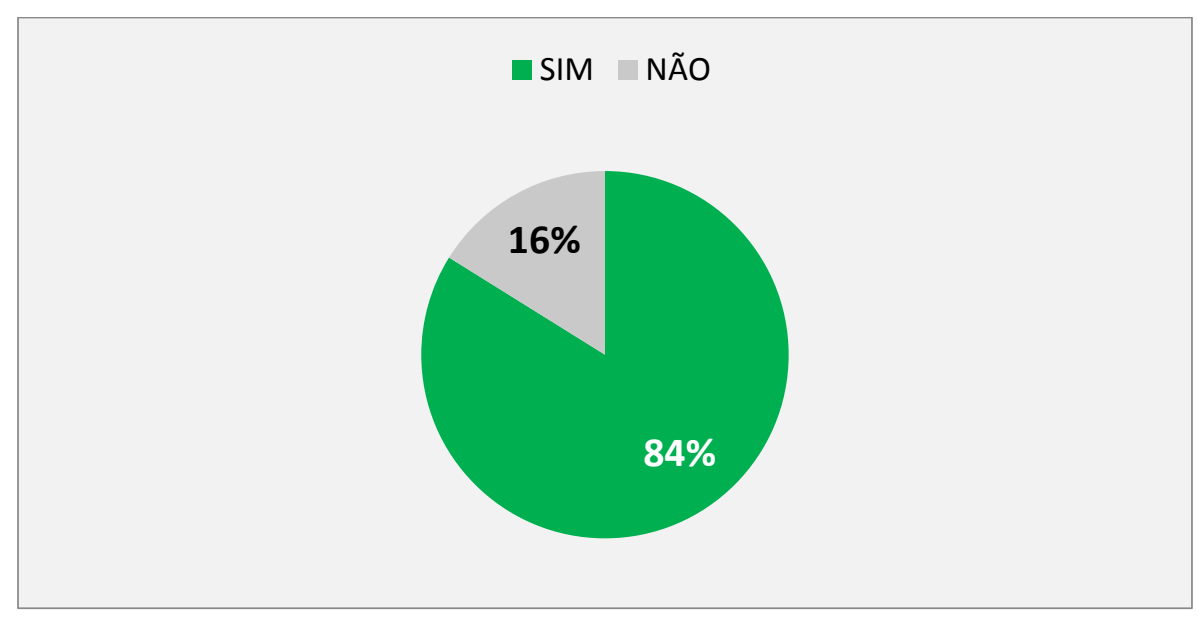

Fonte: Relatório NAT 2011 
A figura 7 representa a citação do Parecer do NAT nas decisões prolatadas pelos magistrados, $84 \%$ dos magistrados mencionaram o parecer do NAT em suas decisões, já $16 \%$ não mencionaram.

Figura 8. Posicionamento do NAT em relação ao pleito

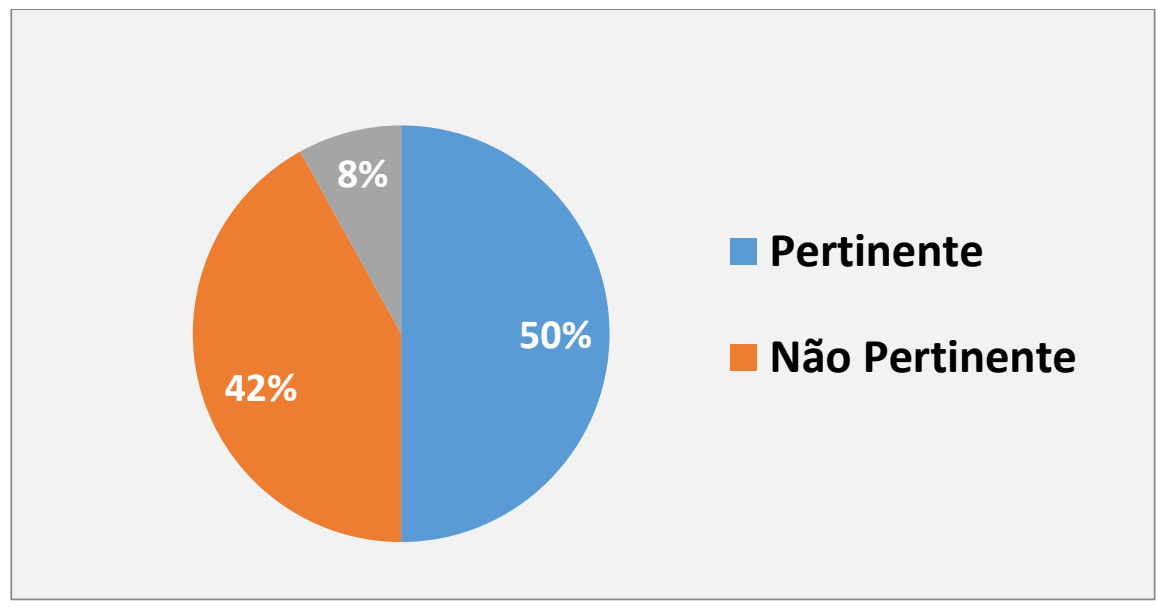

Fonte: Relatório NAT 2011

A figura 8 retrata o posicionamento do NAT em relação aos pedidos realizados em juízo. $50 \%$ dos pedidos apresentados perante o NAT foram pertinentes, $42 \%$ não pertinentes, e $8 \%$ são pedidos que necessitam de mais informações.

Figura 9. Natureza do Pleito

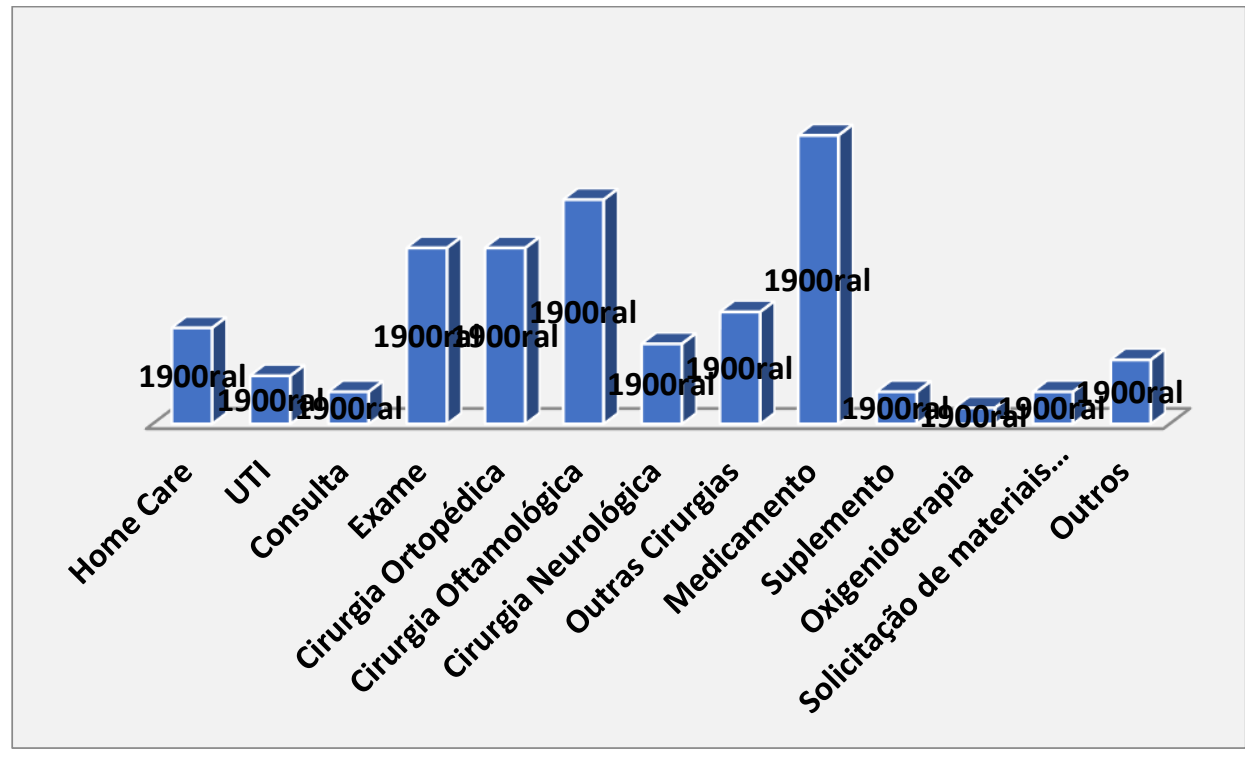

Fonte: Relatório NAT 2011 
A figura 9 apresenta a natureza dos pedidos que chegaram ao NAT. Dos 86 processos: 14 processos de cirurgia oftalmológica, 11 cirurgias ortopédicas, 05 cirurgias neurológicas, 06 Home Care, 03 UTI's, 11 exames, 07 outras cirurgias, 02 consultas com especialistas, 01 oxigenioterapia, 18 medicamentos, 02 suplementos alimentares, 02 solicitações de materiais de cirurgias e 04 outros (cadeiras de rodas, solicitação de botton e Tratamento Fora do Domicílio).

\section{Relação de Processos 2012}

Foram analisadas 1462 demandas, considerando o retorno das atividades em 2012, mais especificamente a partir do dia 01 de janeiro de 2012 a 31 de dezembro de 2012.

Figura 10. Tipo de Processo

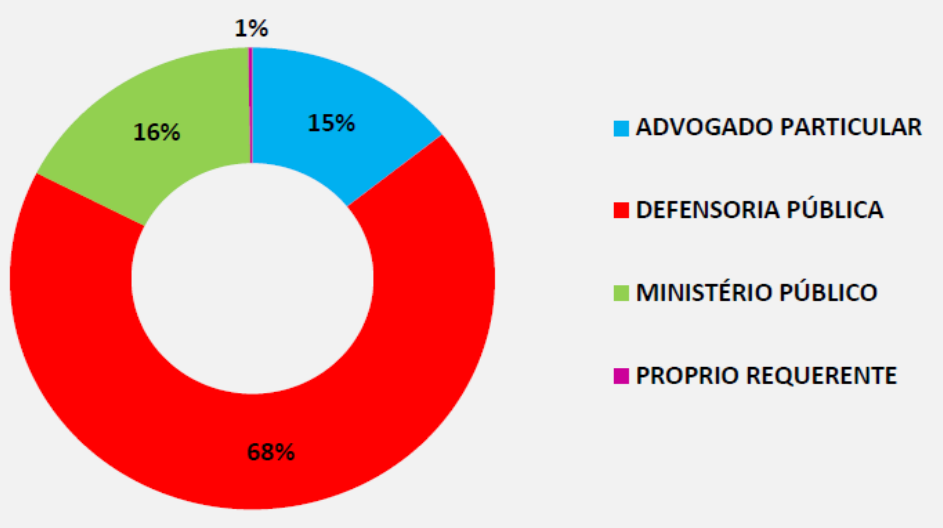

Fonte: Relatório NAT 2012

Dos 1462 processos que passaram pelo NAT, 68\% foram representados pela Defensoria Pública, 16\% pelo Ministério Público Estadual, 15\% através de advogado particular e $1 \%$ apresentado pelo próprio requerente. 
Figura 11. Origem dos Processos

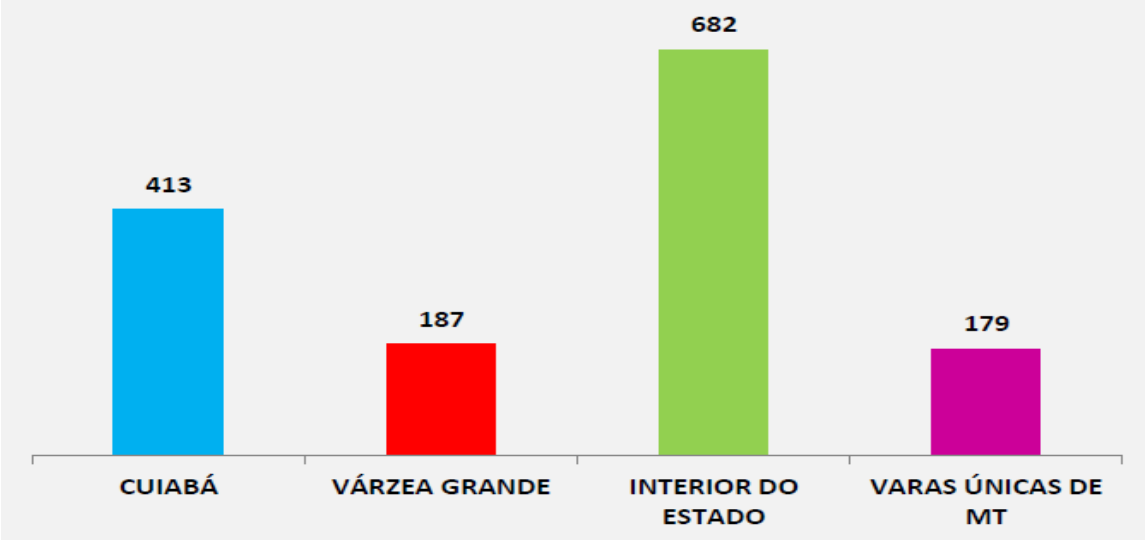

Fonte: Relatório NAT 2012

Foram oriundos da Comarca de Cuiabá 413 processos, 187 das Varas de Várzea Grande, 682 demandas do Interior de Mato Grosso e 179 das Varas Únicas do Interior.

Figura 12. Decisão do Magistrado frente ao Pleito

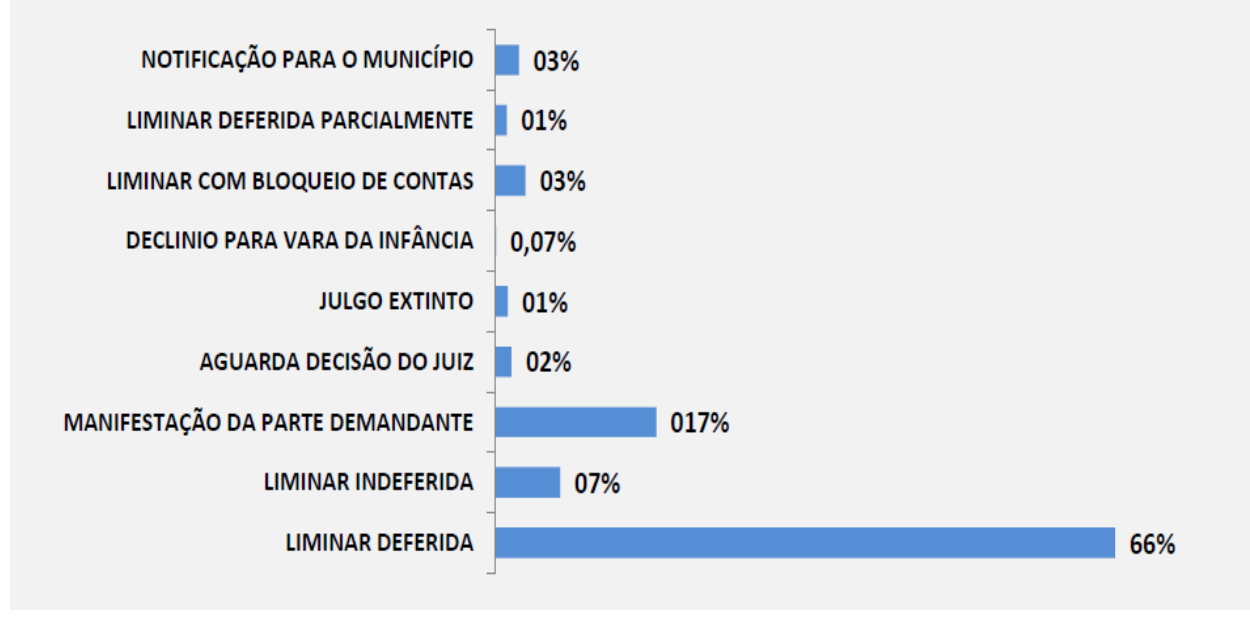

Fonte: Relatório NAT 2012

$\mathrm{Na}$ figura 12, temos a representação da decisão do magistrado frente ao pleito, sendo que: $66 \%$ foram liminares deferidas, $6,9 \%$ liminares indeferidas, $1,2 \%$ liminares deferidas parcialmente, 17,13\% manifestação da parte autora, 0,07\% declínio para Vara da infância, 
2,5\% notificação para o Município, 1,3\% julgou extinto o pedido e 1,7\% aguarda decisão do juiz.

Figura 13. Citação do Parecer do NAT na Decisão do Magistrado

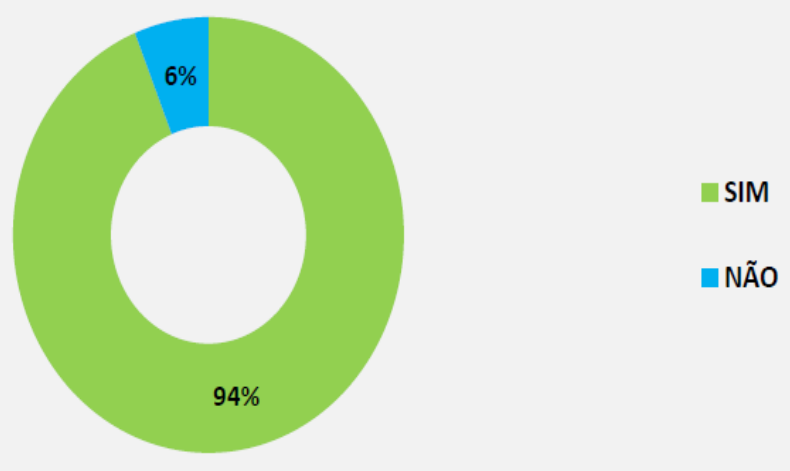

Fonte: Relatório NAT 2012

A tabela 13 representa a citação do Parecer do NAT nas decisões prolatadas pelos magistrados. 94\% dos magistrados mencionaram o parecer do NAT em suas decisões, já $6 \%$ não mencionaram.

Figura 14. Posicionamento do NAT em relação ao pleito

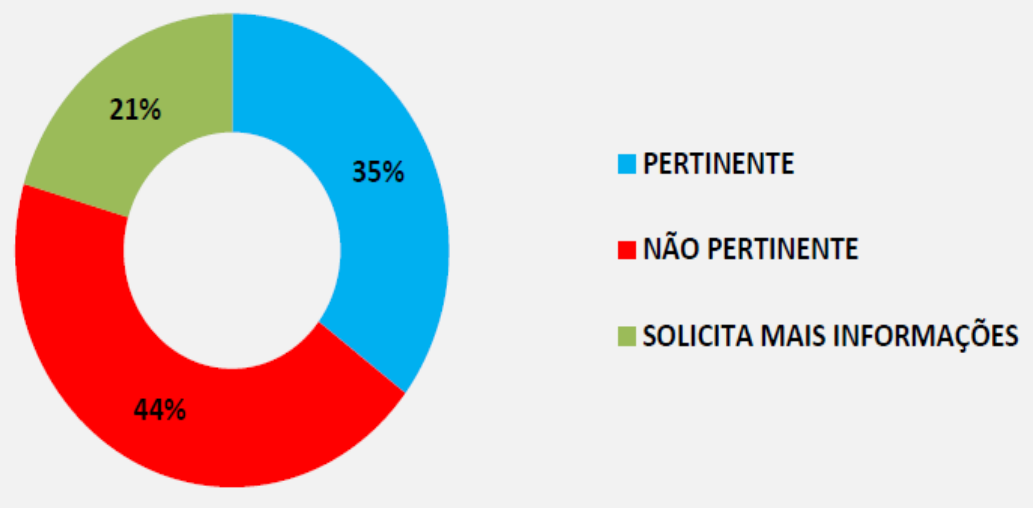

Fonte: Relatório NAT 2012

A figura14 retrata o posicionamento do NAT em relação aos pedidos realizados em juízo. 35\% dos pedidos apresentados perante o NAT foram pertinentes, 44\% não pertinentes e $21 \%$ são pedidos que necessitam de mais informações. 
Figura 15. Natureza do Pleito

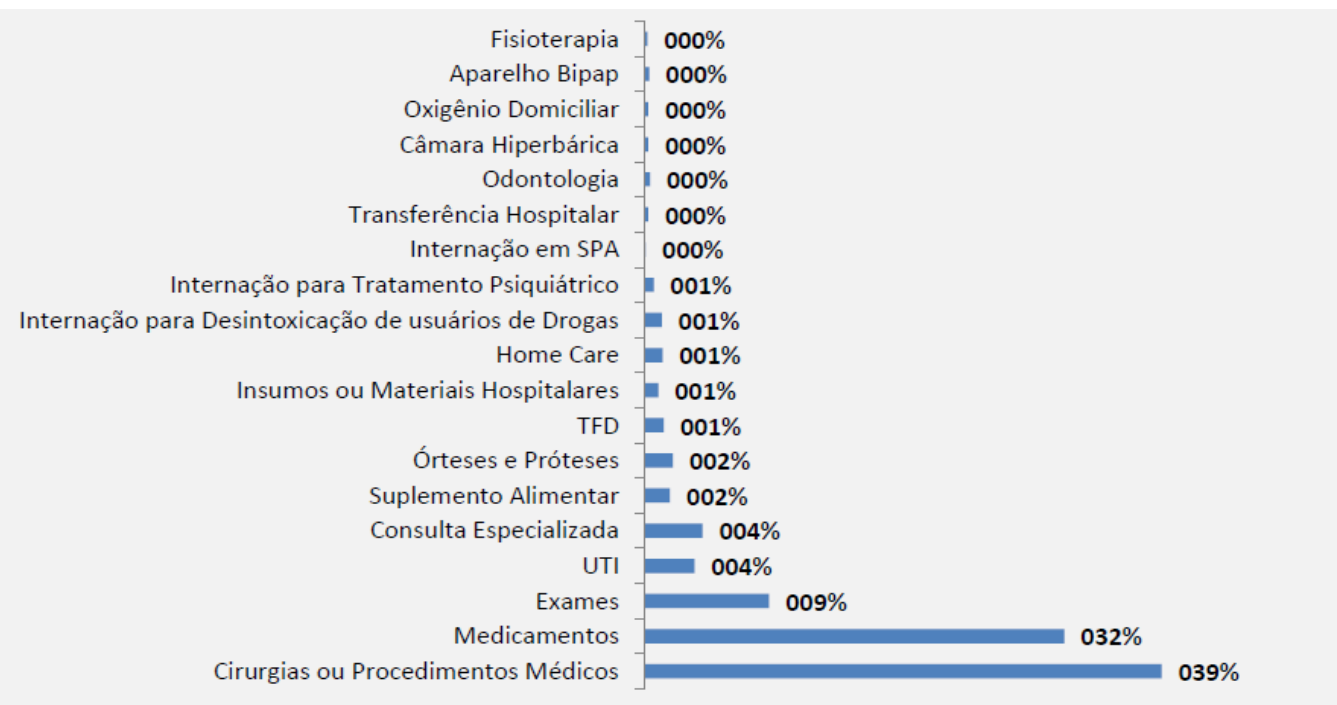

Fonte: Relatório NAT 2012

A figura 15 apresenta a natureza dos pedidos que chegaram ao NAT. Foram 39,09\% pedidos de cirurgias ou procedimentos, $31,72 \%$ de medicamentos, $9,41 \%$ exames, 3,75\% UTI's, 4,37\% consultas médicas especializadas, 1,91\% suplemento alimentar, 2,11\% aquisição de órteses e próteses, 1,43\% TDF, 1,02\% insumos ou materiais hospitalares, 1,36\% home care, 0,68\% de internação para tratamento psiquiátrico, 0,07\%de internação de SPA, $0,27 \%$ de transparência hospitalar, 0,41\% de odontologia, 0,27\% de Câmara Hiperbárica, 0,27\% de solicitação de oxigênio domiciliar, 0,34\% de aparelho Bipap e 0,20\% de fisioterapia.

\section{Comparativo dos anos 2011-2012}

\section{A. Quanto ao tipo de representação}

Pode ser apreendido que os processos em sua maioria são advindos da Defensoria Pública. Em 2011, em segundo lugar, tínhamos os processos originados por advogados particulares, já em 2012 essa posição foi ocupada pelo Ministério Público. Percebe-se que a população está mais consciente de seus direitos e tem exigido do Estado a efetivação do Direito à Saúde, consagrado na Constituição Federal de 1988. 


\section{B. Origem dos Processos}

Da origem dos processos, a sua maioria, em 2011, foi originada da Comarca de Cuiabá, em seguida, do Interior do Estado. Já em 2012, a maioria dos processos é do Interior do Estado, ficando a Comarca de Cuiabá na segunda posição.

\section{Decisão do Magistrado frente ao pleito}

Mais da metade das ações de saúde foi deferida pelos magistrados em 2011 e 2012. Em segundo lugar, no ano de 2011: 18\% das ações foram encaminhadas para manifestação da Defensoria Pública, já em 2012: 17,13\% foram encaminhadas para manifestação da parte demandante.

\section{Citação do Parecer do NAT nas decisões dos Magistrados}

Nos anos de 2011 e 2012, pode-se constatar que os magistrados citaram o parecer do NAT no percentual de $84 \%$ e $94 \%$, respectivamente. Com esse número, pode-se auferir a importância do NAT nas questões judiciais envolvendo a saúde pública no Estado de Mato Grosso.

\section{E. Posicionamento do NAT em relação ao pleito}

O NAT considerou, em 2011 , que $50 \%$ das ações foram pertinentes, em detrimento a $42 \%$ consideradas não pertinentes. Já em 2012, o NAT considerou apenas $34 \%$ das ações pertinentes, e 44\% não pertinentes. Vale ressaltar que o parecer do NAT não vincula o magistrado ao proferir a decisão. O parecer do NAT é apenas técnico. Cabe ao magistrado solicitar ao NAT o parecer.

\section{F. Natureza do Pleito}

A natureza do pleito está em sua maioria na seguinte escala: cirurgias ou procedimentos médicos, medicamentos e exames.

\section{Considerações finais}

O problema da saúde no estado de Mato Grosso está longe de ser resolvido. A cada dia a demanda de ações envolvendo a saúde cresce no Fórum da Capital. O NAT tem 
exercido seu papel, analisando caso a caso mediante pareceres técnicos de profissionais da saúde.

Percebe-se que há vários casos considerados não pertinentes pelo NAT, ou seja, são casos que não há respaldo legal para o pedido. O que acontece é que muitas dessas ações poderiam ser resolvidas por políticas públicas, muitas vezes existentes, mas desconhecidas ou realizadas precariamente, que resultam ineficientes.

É necessário que essa questão da saúde seja retirada do âmbito do Judiciário, visto que o cidadão recorre à justiça a fim de buscar decisão para seu caso, e o judiciário não pode abster-se de julgar nenhuma lesão ou ameaça a direito.

É possível verificar que a população cada vez mais está consciente de seus direitos e exigindo que o mesmo seja efetivado através de decisões judiciais, visto que a ação do Poder Executivo na saúde resta ineficaz, não alcançando a população que procura por esses serviços. Enquanto não houver um debate coletivo com os atores sociais e os três poderes quanto à situação da saúde no Estado de Mato Grosso, estaremos diante desse cenário de aumento de ações envolvendo a saúde, pois o cidadão não pode ficar à mercê da ineficácia de gestão dos Poderes Públicos.

O papel do Estado de Mato Grosso é ampliar o debate da questão da saúde junto aos movimentos sociais a fim de efetivar a saúde no Estado por meio de políticas públicas eficazes, com a população exercendo o controle social dessas ações.

Esse trabalho apresenta desafios para a gestão pública do Estado de Mato Grosso, que se vê diante de um cenário de reestruturação quanto a discutir a questão da saúde no Estado, o que tem trazido consequências para o planejamento da referida área.

\section{Referências}

1. World Health Organization. Constitution of the World Health Organization. Basic Documents. WHO. Genebra. 1946. [Acesso em 17 de out. de 2016]. Disponível em http://www.who.int/governance/eb/who_constitution_en.pdf.

2. Brasil. 8a Conferência Nacional de Saúde. Relatório final. [Acesso em 22 dez. 2014]. Disponível em http://conselho.saude.gov.br/biblioteca/Relatorios/relatorio_8.pdf. 
3. Sarlet IW. A Eficácia dos direitos fundamentais: uma teoria geral dos direitos fundamentais na perspectiva constitucional. 10 ed. rev. atual. e ampl. Porto Alegre: Livraria do Advogado, 2009.

4. Lenza P. Direito Constitucional Esquematizado. 13 ed. rev. atual. e ampl. São Paulo: Saraiva, 2009.

5. Silva JA. Curso de Direito Constitucional Positivo. 28 ed. rev., atual. São Paulo: Malheiros Editora Ltda, 2007.

6. Anne Joyce Angher, (org). Constituição Federal de 1988. VadeMecum Universitário de Direito Rideel.. 11 ed. atual. São Paulo: Rideel, 2012.

7. Figueiredo MF. Direito à Saúde. 2 ed. rev., ampl. e atual. Bahia: Editora JusPodivm, 2011. p.19

8. Ministério da Saúde. Anais da 3ª Conferência Nacional de Saúde. Niterói: Fundação Municipal de Saúde,1992. [Acesso em 28 jul. 2016]. Disponível em http://bvsms.saude.gov.br/bvs/publicacoes/cd07_01.pdf. p. 03.

9. Paim JS. Reforma Sanitária Brasileira: Contribuição para compreensão e crítica. Salvador: Editora Edufba/FIOCRUZ, 2008. p. 101.

10. Teles V. OMS quer conhecer modelo brasileiro de saúde. [Acesso em 22 dez. 2014]. Disponível em http://portalsaude.saude.gov.br/portalsaude/noticia/4214/162/oms-querconhecer-\%3Cbr\%3Emodelo-brasileiro-de-saude.html.

11. Paim JS. O que é o SUS. Rio de Janeiro: Editora Fiocruz, 2009. p. 13-15; 19; 33; 44.

12. Sarlet IW. Algumas considerações em torno do conteúdo, eficácia e efetividade do direito à saúde na constituição de 1988. Revista Eletrônica sobre a Reforma do Estado (RERE), Salvador, Instituto Brasileiro de Direito Público, $\mathrm{n}^{\circ} 11$, setembro/outubro/novembro, 2007. [Acesso em 27 dez. 2014] Disponível em http://www.direitoestado.com.br/rere.asp. p. 9; 12.

13. Gandini JAD, Barione SF, Souza AE. A Judicialização do Direito à Saúde: A Obtenção de Atendimento Médico, Medicamentos e Insumos Terapêuticos por via Judicial - Critérios e Experiências. [Acesso em 27 dez. 2014] Disponível em: http://www.ambitojuridico.com.br/site/index.php?n_link=revista_artigos_leitura\&artigo_id=4182. p. $1 ; 10$.

14. Ventura M, Simas L, Pepe VLE, Schramm FR. Judicialização da saúde, acesso à justiça e a efetividade do direito à saúde. Physis, Rio de Janeiro, v. 20, n. 1, 2010. [Acesso em: 27 dez. 2014]. Disponível em: http://www.scielo.br/scielo.php?script=sci_arttext\&pid=S0103$73312010000100006 \&$ Ing=en\&nrm=iso. p. $10 ; 11$.

15. Gontijo GD. A judicialização do direito à saúde. Revista Médica de Minas Gerais RMMG, América do Norte, 202102 2011. [Acesso em 27 dez. 2014]. Disponível em:http://pesquisa.bvsalud.org/regional/resources/lil-577597. p. 145; 607. 
16. Barroso LR. Da falta de efetividade à judicialização excessiva: direito à saúde, fornecimento gratuito de medicamentos e parâmetros para a atuação judicial. [Acesso em: 4 jan. 2015]. Disponível em: http://bdjur.stj.jus.br/dspace/handle/2011/38245. p. 24.

17. Conselho Nacional de Justiça. Núcleo técnico discutirá demandas judiciais de Saúde no MT. [Acesso em: 27 de dez. de 2014]. Disponível em:

http://www.cnj.jus.br/noticias/cnj/16847-nucleo-tecnico-discutira-demandas-judiciais-desaude-no-mt.

18. Lakatos EM; Marconi MA. Metodologia do trabalho científico. São Paulo: Atlas, 1995.

Submetido em: 15.jun.2016

Reapresentadoem: 4.ago.2016

Aprovado em: 14.dez.2016 